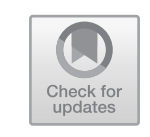

\title{
Fragile Time: The Redemptive Force of the Urarina Apocalypse
}

\author{
Harry Walker
}

\section{INTRODUCTION}

That the world as we know it is on the brink of collapse is a recurring theme among the Urarina people of Amazonian Peru. In this, of course, they are far from alone: generalized anxiety about the future of humankind might well be almost as old as humankind itself, but seems today on the rise as never before. Apocalyptic thinking is certainly prevalent among the native peoples of lowland South America where, as more than one commentator has pointed out, it has a solid historical precedent, insofar as the world already ended at least once before with the arrival of Europeans some five centuries ago (e.g., Bessire 2011; Danowski and Viveiros de Castro 2017: 104; Neves Marques 2015). Between 1492 and 1610 some $95 \%$ of Amerindians are believed to have died: a mass

The original version of this chapter was revised: This chapter was previously published as non-open access. It has now been changed to open access under a CC BY 4.0 license. The correction to this chapter is available at https://doi.org/10.1007/978-3-030-13860-8_11.

H. Walker $(\bowtie)$

London School of Economics and Political Science, London, UK

e-mail: h.l.walker@lse.ac.uk

(C) The Author(s) 2019

R. Bold (ed.), Indigenous Perceptions of the End of the World, Palgrave Studies in Anthropology of Sustainability, https://doi.org/10.1007/978-3-030-13860-8_3 
extermination so catastrophic that the resulting shift in land use patterns led to a dramatic global drop in carbon dioxide emissions, the so-called Orbis Spike that has been proposed as a good candidate for dating the start of the Anthropocene (Lewis and Masin 2015). At this same time, of course, trade became truly global as the two hemispheres were connected, the New World meeting the Old in a geologically unprecedented homogenization of the Earth's biota (Lewis and Maslin 2015: 175).

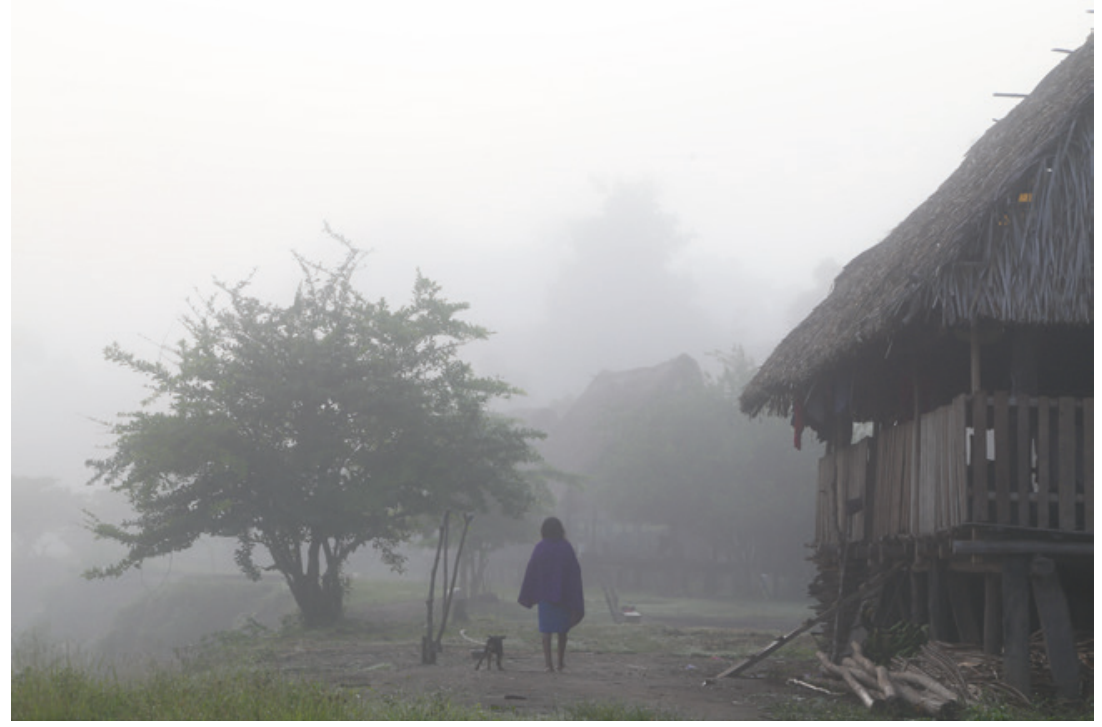

For those native peoples of the Americas whose lives were most directly affected, however, the local ecology was already highly anthropogenic; so far as they were concerned, they had always lived in the Anthropocene. That is to say, human action was never really decoupled from atmospheric, geologic, and hydrologic processes; nature and culture, or the cosmological and the anthropological, were never separate. This is of some relevance to us here today, as we finally draw a similar conclusion, right about the same time we are confronted with own narratives of impending disaster. The fragility of the climate, its surprising dependence on human activity, and its shifting nature as a moral and social as well as a technical problem are just some of the areas of common ground that seem worthy of further exploration.

What is of interest for us here, as we struggle to think through the challenges that surround effective governance of the global commons, is more than the Urarina people's careful custodianship of their planetary 
ecology. I want to draw attention to their acute sense of the weather or climate itself as a common good to be collectively maintained, even collectively produced. In exploring in this chapter how the Urarina are thinking about the imminent end of days, I hope therefore to provoke reflection on the very concept of weather and its relationship to time, and how these together implicate particular forms of agency and responsibility. I wish to show how, according to Urarina apocalyptic discourse, catastrophic climate change is a moral and social as well as technical problem; one over which we do have some influence, even if it is never something we can fully hope to master. When it comes to the apocalyptic we are always in the presence of the mysterious and the unveiled. This is surely something we should never lose sight of if only because it is part of the way in which eschatology, or the theory of final events, imbues life with a sense of structure and purpose.

At the end of the day, however, for all the common ground-our common predicament, as it were-we should bear in mind that there is more than one end of the world: that is to say, the ends of the world are many. There is something quite specific about the end of the world as it is imagined by the Urarina people, and revealing this means also coming to terms with Urarina visions of the world as potentially shaped by, and in turn helping to shape, a specific but diverse range of social, historical, and material factors, from the often turbulent nature of contact with outsiders, to their particular conceptions of the good life, to the ways in which people experience the everyday ebbs and flows of their local riverine environment. And it means paying careful attention to what they have to say about the time we have remaining.

\section{Times of Fragility and Decay}

I met Custodio at the end of 2005. He was in many ways the last of his generation, living a modest but highly mobile existence with his youngest wife and small children, now too old to hunt or work in the garden but still able to eke out an existence and maintain his independence. He died just a few months after I met him, and his passing was acknowledged by virtually everyone in the area as a significant event, given his prodigious wisdom and his steadfast dedication to the ways of the ancients. Unlike his more sedentary children and grandchildren he still spent his life on the move, constantly traveling and visiting his many descendants, unwilling or unable to stay still for long. He expressed 
eloquently the lingering dread that I soon learned many others also felt, concerning a near future rushing headlong toward us, a future that nevertheless recalls and in some ways repeats a distant past. His words are well worth quoting in full:

A long time ago, it's said that our land was destroyed. The sky fell, it's said. It fell to the level of the forest. Everything was destroyed. The ancient people drank ayahuasca, and in that way managed to detain it, up until today. That's why we are afraid. And so we should be afraid! Each month, when the moon is full, it might fall down, finishing us off. How huge must it be? It would completely destroy us! It would destroy the land, destroy our epoch. Then we'd all be completely lost. Otherwise, a tremendous earthquake will cause the land to fly. It will fly away immediately, as though it were made of cotton! And so we'll all be lost. We'll no longer be like people. Otherwise, it will grow dark. We'll lose our marker, the sun. When the sun disappears, there'll be nothing but darkness. Nothing even to make a fire with. It'll be as though our eyes were shut. Jesus Mary, poor little God! Otherwise, the thunder will make a tremendous noise and the lightning will piss down on us from the sky, burning everything, like gasoline it will burn! Boom! Here and there, all around us, the land will sink immediately. Everything that lives will suddenly perish. That's what the ancients said. So yes, please, be afraid, God bless. God who created us. In this way I beg God to bless me. We share food with everyone, don't be stingy, that's what the ancient people said, or God will punish us. Eating together, we can beg God to let the animals appear in the forest. If he turns his back on us there will be no animals whatsoever for us to eat. A great fire will come. "Where is God now?" they will ask, burning in the fire.

All the Urarina I spoke to about the end of the world assented to this narrative, or something roughly similar. There are several points about it worth noting. First, the end of the world is marked by a rapid deterioration in the weather, including a number of elemental forces that pose an immediate danger to life on earth, including the possibility that the moon will fall out of the sky. Second, what is actually about to end is cana cojoanona (literally "our days"), which I translated as "our epoch"-suggesting a cyclical calendric of sorts. Third, the end is apparently linked to a decline in good behavior, suggesting an important connection between the earth's climate and the moral order. Finally, the world in fact already ended, a long time ago-although it was effectively restored and stabilized by diligent drinkers of ayahuasca, thus carving out an important space for human agency. 
To take the last issue first: what should we make of the apparently paradoxical assertion that the end of the world has already taken place, that the sky has already fallen, sometime in the distant past, and this is why the world remains so fragile today? As noted above, it is tempting to point to the obvious historical correlate for an end of the world that already happened: as Harkin (2012: 97) put it, "For Native Americans in the wake of European contact, the changes were so extreme that they were viewed on the level of the mythical events that led to the creation of the world itself." There is, however, also a certain millenarian element to this discourse, which seems inflected in some way with Christianity, with varying degrees of explicitness. Consider the following story about how the Urarina people were abandoned by God long ago:

So much did we annoy our Father that he passed over to the sky. With a cross he went, so it's said. And everything over here in our world began to break down. Even today, it's still broken, our world is going to end. It's on its way. That's why, they say, the animals too want to return [to the sky], they want to go back, because it's like this. The mestizos also say this. It's made it up to now, but the world will be annihilated. When the mestizos knew this, they said it too. Yes, they said, it's going to end. All our world, our land. The ancients knew. It will be extremely dangerous. The demons, the unknown ones, are already talking.

Although there were virtually no functioning Urarina churches at the time of my fieldwork and very few if any Urarina could really be considered Christian, it is worth emphasizing that they have had a relatively long history of exposure to Christian ideas and influences. They were first contacted by Jesuit missionaries in the seventeenth century, and for part of the eighteenth century several hundred Urarina lived in the mission settlement of San Xavier de Urarinas, founded on the banks of the Chambira River. The Jesuits were expelled from Peru in 1767, and the Urarina have probably had intermittent contact with Christianity ever since. Christian, especially Catholic, themes are discernible in some of their most well-known myths, which tend to superimpose newer, Christian characters and motifs over pre-existing ones, while recognizably Christian images have been incorporated into ayahuasca-based shamanic chanting. Even shamanic visions blend a recognizably Christian apocalyptic with recognizably Amazonian themes. 
It is also true that apocalypticism of the kind we are dealing with seems often to be a discourse employed by subaltern peoples with a history of subordination or exposure to violence. In the words of Fenn (2003: 110): “At times of crisis, when a way of life seems threatened with extinction, the apocalyptic imagination is liable to flare up with special force. In these circumstances, predictions of an imminent end may take on new plausibility." Yet memories of the past are also re-interpreted and re-shaped in light of more recent events, especially those that tend to provoke anxiety and uncertainty. Among the Duna people of Papua New Guinea, according to Nicole Haley, the apocalyptic vision "problematizes the space development inhabits, through its claim that mining will bring about the end of the world ... [and] allows Duna men and women to comment and reflect upon the loss of control they sense concerning the future" (Haley 1996: 285). In the native Americas, concern about the end of the world is similarly sometimes linked to a history of colonialism as well as ongoing dispossession and violence: according to Lucas Bessire, for instance, so-called "apocalyptic futurism" among the recently contacted Ayoreo peoples of the Paraguayan Gran Chaco has become "a potent explanatory framework for understanding or creating past events," one that essentially "translates extreme experiences of violence into the conditions for human existence." As Fenn (2003: 110) poignantly put it, "For those who find the present world offering too little in the way of satisfaction or too much in the way of uncertainty, apocalypses satisfy the desire to wipe out the world and, with it, the last vestiges of the singular self."

In short, it seems that apocalyptic futurism among the Urarina might usefully be understood in part as a response to colonialism, violence, and the deep sense of uncertainty that accompanies a rapidly changing world. A sense of disjuncture between the generations, reflected in everything from musical tastes to aspirations to styles of speaking, no doubt exacerbates a certain sense of loss in the face of an unknown future. Older people, in particular, often comment that the end of the world is directly tied to the demise of the powerful shamans of times past; the younger generation is, moreover, simply unwilling or unable to replace them. They are widely perceived to lack, in particular, the physical discipline required to diet or abstain for prolonged periods of time, to build up potency. "They're not strong," I was told. "They'd rather listen to cumbia on their stereos." Yet, while factors such as these contribute to rendering this particular historical moment as one of crisis, a range of other factors must also be taken into account, ranging from people's everyday 
experience of their immediate physical environment, to the lived experiences of decay and how this informs temporalities, as well as the ways in which the Urarina people assert their own sense of temporal agency.

\section{Life in A Fluid Cosmos}

Like many other native Amazonian peoples the Urarina live a mostly subsistence lifestyle, based around hunting, fishing, and small-scale slash-and-burn agriculture, supplemented by occasional work for itinerant traders. Houses are relatively simple structures, built from materials found locally and somewhat open to the elements, as very few have walls. Most travel is by dugout canoe, although these days often powered by small outboard motors. Their territory is remote, far from any towns or urban centers, and the rivers on whose banks they build settlements are dark and sinuous, leading nowhere, meaning that visitors are few, for no one passes through on their way somewhere else. The land is flat and low-lying with abundant swamps; the clayey earth quickly turns to mud in the heavy rain.

This is a fluid cosmos. Bodies and flows of water orient people's lives, beginning with the rivers themselves, on whose banks they dwell and which provide sustenance as well as the primary sense of spatial orientation, in the all-pervasive distinction between "upriver" and "downriver." Cosmogonic myths tell of a primordial flood that marked the beginning of the current era; the existence of such myths are easy to comprehend once having witnessed the torrential rains which can all too easily appear as though they're never going to cease. All this water that passes through Urarina territory both comes from, and eventually ends up in, cana temura (literally "our source"), an infinite expanse of water said to encircle the land on all sides and where the terrestrial plane joins the celestial. In short, water is all around, above, and below; people effectively inhabit a tiny patch of land poised precariously above an inconceivably vast ocean, and are continually inundated by yet more water from above. These flows of water are the source of life but they also degrade, corrode, and transform: not least the river itself, whose banks are perpetually washed away and re-deposited, with the effect that the world's primary spatial axis is itself in constant movement.

Given such a fluid cosmos, it is perhaps little wonder that people affirm that when the end of the world comes the sky will fall, the land will sink, the rivers will transform into mud (or fat), and everything will gradually turn into liquid. "All that is solid melts into air," to coin 
a well-known phrase (Marx and Engels 2010 [1848]), suggesting the power of liquefaction as a metaphor for the erosion of old certainties.

In fact, the world itself is thought to be in a highly fragile and precarious state; not only in a constant state of decay, but perpetually on the brink of collapse. What is about to collapse is, more specifically, cana cojoanona, a pivotal concept that literally means "our days" and is the backbone, as it were, of Urarina cosmology. ${ }^{1}$ Loosely, cana cojoanona is perhaps a little similar to the English term "world," in the sense of "that in which we dwell," or the earthly state of human existence, and indeed is occasionally translated into Spanish by the Urarina themselves as mundo. But more often it's translated as nuestro tiempo ("our weather" or, alternatively, "our time"). This is felicitous because Spanish, like Urarina (and indeed many other languages), uses the same word for both "time" and "weather," pointing of course to an intrinsic connection between these two phenomena that is largely lost to those of us living lives largely sheltered from both the fluctuations of the weather and its importance in marking the passing of time. For the Urarina the notion of weathertime clearly has a kind of epochal quality - the "current era," as it were; we might also think of it as akin to what Tim Ingold calls the "weather-world," in which we are immersed and in which nothing stands still, where "every being is destined to combine wind, rain, sunshine, and earth in the continuation of its own existence" (Ingold 2007: S20). But the concept designates more than just a horizon of being, or precondition for life, because humans are also involved in its ongoing production.

The most salient characteristic of cana cojoanona ("our epoch" or "our weather") is its extreme fragility. By all accounts it's been in a precarious state at least since the time long ago when the world first "ended." As my friend Bolon once put it, the climate is literally "hanging by a thread," swinging to and fro like a hammock. Here are his words in full:

Before, in the time of our creation, the world ended. Darkness fell and there was permanent night. It's said there was an old drinker of ayahuasca. It's said that our animals weren't there anymore. The land was completely devoid of animals. Day never broke, it was never dawn. That drinker of ayahuasca, he drank and he saw that the world was ending, without dawn, and suffering with ayahuasca. He was the defender of the world. Because of him, dawn broke. And the animals began to walk around. Those who are seeing the world today - they will see its end. Thanks to that drinker of ayahuasca the world is still hanging by a thread, swinging to and fro. Truly, our lives are tremendously fragile. It's in great danger now, our world. 
It seems to me that the fragility of the world and its imminent end is in many ways a logical extension of the phenomenological experience of decay and decline that pervades everyday life. What I mean is, as I've mentioned, everything deteriorates in the fluid Urarina cosmos. In fact, most things in people's lived experience deteriorate remarkably rapidly. The Amazon rainforest is a harsh environment, let's remember: when I once commented to a mestizo trader how quickly the Chinese-made stereos he sold to my Urarina friends seemed to break down, he joked that he could sell them a perfect sphere made of steel and it would break before too long. It's just how things are in this part of the world. And this is one reason, conversely, why highly durable objects such as stones are ascribed extraordinary power and value; or why the most prized types of wood are inevitably those that are hardest and thus slowest to rot. Yet stones, too, like wood and everything else, are eventually corrupted. In this view it seems logical enough that the world, our epoch, would also be subject to degradation. Perhaps the degradation rate of the world is to that of a stone what that of a stone is to that of a fruit. In other words, in short, cosmological entropy would seem to have a phenomenological basis in the pervasive everyday experience of disintegration and decay.

\section{Moral Decline as Climatic Disintegration}

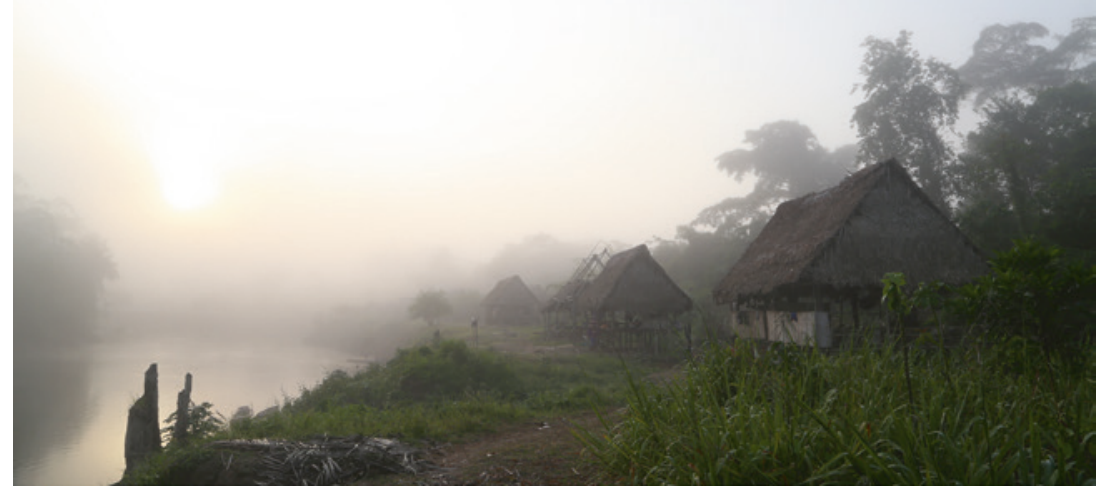


If everything eventually perishes in this fluid environment-and often sooner rather than later-that is not to say the process of deterioration is entirely outside human control. Steps can sometimes be taken to slow or even momentarily halt the process, from adding salt to meat or fish, to wrapping especially delicate or valuable items, from radios to feather headdresses, carefully in cloth or plastic to protect them. So even entropy on a cosmic scale is not entirely divorced from human action.

Take the example of rain. Even if it is a necessary part of life, people generally dislike rain and speak of it negatively. This is unsurprising if we consider how rain halts the time of everyday life, preventing people from hunting, gardening, or working, forcing them to sit idly in their houses, which no one particularly enjoys. Rain is sometimes referred to as cana choaje necalano, literally "filth in the sky" or "filth overhead". When it rains for several days continuously, people start to talk about the end of the world growing near. Strong winds, too, threaten to finish off the world, and thus can frighten people. It becomes harder to find animals in the forest, and there's a general sense of scarcity and deprivation. But rain can also sometimes result from human carelessness. Bathing in the river right after planting manioc, for instance, is said to result in rain. A friend of mine once admitted to me his responsibility for a severe rainy spell, explaining that his wife had inadvertently washed in the river an old rag he had used to blow his nose while drinking ayahuasca the night before.

The gradual decline of game in the forest, of which the Urarina are all too aware, is linked by them less to overhunting, or the introduction of shotguns, than to a general sense that the climate itself is changing and declining over the long term. My friend Lucho would often complain that when he was younger the seasons were regular and one could rely on certain ecological processes to mark out a calendar of sorts: certain flowers and fruits could be expected to appear at the same time each year; and so on. But this was no longer the case, for the seasons are growing increasingly chaotic. This recognition of climate change is closely linked by the Urarina to the growing fragility of the climate itself.

More severe lapses in people's behavior are thought to accelerate the process of disintegration, drawing the end nearer still. One person explained it as follows: "when we eat together, we live like real people. But when our thoughts are different [i.e., when we're stingy], when Our Creator scolds us, the world that he gave us will end." Or, as someone else put it, "Some people go around attacking each other, exterminating each other, thinking differently." But one who sees that all is well in his life, 
he can say, "no, that's not it." He can say, "that's not for our own good. The world will end in this way, that which Our Creator gave us. If we carry on like that we'll all be lost, together with our world. Everyone."

Closely linked to declining morals and a deteriorating climate is the appearance of demons known as coitecuchui (literally "the unknown people"). It seems to me that their presence is somehow linked, in the Urarina imaginary, to the act of incest. In the words of Tivorcio:

Those evil ones, those demons, the unknown ones (coitecuchui), they're going to arrive here. They look just like people. "Where do they come from," we can ask, "these people who we don't know?" And later, the one who knows a little, the one who drinks ayahuasca, can say, "those ones who we don't know, they're taebuinae ('savages, demons, bad ones'). They're coming here where we live, it seems they're coming to talk to us, but they're coming to kill us, to eliminate us." That's what we all can say. And so it was for the people who know a bit, the old people, the people who were before us, and so it will be for those who follow us, those who replace us on earth. That's what the ancients said, speaking of all the demons, all the ghosts, all the unknown ones. They are already arriving in some places. This is what people are saying.

Discussing this later with my friend Elias, who helped me translate this passage from the original Urarina, he added some thoughts of his own:

For example, they've been arriving in [the community of] Pijuayal, Dos de Mayo, and talking to the people there. "I'm your friend, I'm just like you, I'm also like this." That's what they say. The demons arrive where the people are having sex with their mothers-in-law, where they're having sex with their mothers. That's where they're arriving, and that's where the people are talking about it.

Elias went on to say that when he was in the community of Nueva Esperanza a while back the people there warned him that some demons had recently arrived in the community of Dos de Mayo, and had wanted to give out tins of food among other things, before simply disappearing right in the middle of the football field. Others disappeared into the ground and vanished. He was told that the frogs there were speaking, just like people, calling out, saying, "I'm your friend, I also have my family!" and suchlike. "When the demons talk like that, it always rains, every day," Elias told me. "The weather is terrible." 
Speaking again of the demons that will roam the earth, one man told me, "When the world is going to end, just a few days before, the coitecuchui will come out and burn the world. And they'll say to us, 'you have left God, and you want to have sex with your family'." Some people are thus understandably on the lookout for such demons in everyday life, along with other strange and disturbing occurrences that signal to people that the end is near. One such sign is that animals start talking-comprehensibly, that is, in the Urarina language. Thus one man told me of his alarm when he had a dream in which two cows started chatting to him. There is, it might be pointed out, a throwback here to mythical times, to a now distant past when animals communicated readily with humans and were not yet fully differentiated.

Ideas such as these can easily come to color everyday experience. To give another example: in June 2017 the village was abuzz with rumors and a general state of anxiety after my neighbor Castañon, a quiet and serious man in his late forties or early fifties, was returning home in his canoe late one night when he saw two people swimming across the river. Notwithstanding the fact he was returning after an evening spent drinking manioc beer, the occurrence was soon connected to another rumor then doing the rounds, according to which a group of people from the upstream community of Pijuayal had been drinking manioc beer when two young men they didn't recognise, apparently Urarina, appeared in their midst, seemingly from out of nowhere. When someone from the group asked where they were from, they replied that they were from the community of Santa Rosa de Siamba, which is about a day's travel by boat upstream. The group invited the men to come drink with them, upon which they suddenly ran away into the forest-something everyone found most unusual. The next morning the group called Santa Rosa de Siamba by two-way radio to ask about the men, but their interlocutors knew nothing and said that all members of the community were there at present, that no one was traveling or missing. Different people drew different conclusions from this strange event, but at least one person I spoke to concluded that these two strange men were probably demons heralding the imminent end of the world.

We return here, of course, to the millenarian and potentially Christian elements of the apocalyptic vision that I mentioned earlier. Here is how one person conveyed to me their fears: 
If the earthquake doesn't punish us, the lightning will, burning the land. This punishment will affect the "sinners" who have sex with their family. Mother, aunt, sister. God will choose the "good" men and take them to the sky. The sinners will sink with the land. The canoes will transform into alligators, which will attack the men, as will the demons (coitecuchui), and the mothers of the forest, of the great trees. The demons will transform into the shape of people and come to converse with those who commit incest.

Consider, too, the following story, told to me by Martin the day after he drank ayahuasca, when I asked him what he saw in his visions. He replied that he was advised that God wishes to "collect" all the people who drink ayahuasca and who believe in him; that he "doesn't agree" with people staying here in the world anymore. "It's not like it was before," according to God. The world is approaching its end, and when all those who believe in him have been removed to safety, to be with God, the land will sink and with it all "those who believe in the inferno." For what it's worth I suspect this is a syncretic vision, mixing new and old beliefs: that in the absence of any mass conversion to Christianity, such a discourse would only spread if it resonated with earlier ideas and precepts. In any case, many people told me that in one way or another poor behavior will bring about the final end. In short, the decline of the climate is inseparable from a general condition of moral decline. At the same time though, this helps to shift the burden of responsibility to humans themselves. Like good behavior, in other words, a good and stable climate is potentially within human control.

The constant threat of declining moral standards appears consistent with a broader sense of continuous loss that extends well beyond the physical landscape. As Ballard observed for the Papuan Huli, "Entropy might appear somewhat glib as a label for the wide range of attitudes, perceptions, and dicta that are articulated by the Huli on the general topic of decline" (Ballard 2000: 207). Prominent in many Urarina people's minds, as noted above, is the dissipation of knowledge and wisdom resulting from the demise of the great drinkers of ayahuasca of the past. Young people seem too weak and lacking in self-discipline to ever replace them, and great uncertainty surrounds the current moment of rapid social and cultural change. People are scornful of city life in particular: when compelled to travel to urban centers, for instance, to sell forest produce or embark on bureaucratic tasks, they frequently complain about the lack of sharing, or the shameless 
stinginess of local residents: how no one ever invites them to drink plantain soup or manioc beer; how one cannot do anything if one lacks money. With mounting anxieties about an uncertain future in which even the knowledge of the ancients seems an inadequate guide, it's difficult to escape the sense that people are headed for a time of darkness in which the light of knowledge grows ever dimmer. And yet, there is still hope.

\section{REPAIR AND REDEMPTION}

The Urarina people often say that a giant jaguar lives in the sky, and that it regularly fights with the moon. This is the usual explanation of the moon's blood red color at times of lunar eclipse. As the jaguar scratches and claws it the blood flows forth, resulting in a dangerous time for all, for if the jaguar kills the moon it will fall from the sky. The jaguar will follow it down to earth, and when it encounters humans it will easily finish them off. Similar beliefs appear to have been held by many other Amerindian peoples, including the Mayans and the Incas, who would apparently take up their spears and shout at the moon to keep it away (Lee 2014). The Urarina people also saw scope for human intervention: I was told that at times of lunar eclipse the ancients would all go outside in an attempt to save the world from destruction, praying that the moon not fall to earth. Some would shout and beg, others would shoot blowpipe darts, specially "blessed" by specialists, at the jaguar to frighten it. Sometimes, I was told, they would enter its flesh, scaring it away. My friend Martín told me that his grandfather would "bless" ashes from the fire, placed in a bowl and covered carefully with cloth, and then send the womenfolk out to throw it at the sky, until all the ashes were finished. In this way, he said, the sky "normalized" once again.

Ultimately, however, many agree that only God can choose to postpone the end of world, and persuading God is best done by shamans in their state of trance. Thus I was told that "when the ones who drink psychotropics no longer exist, there will be no food to eat, nothing at all, people's hearths won't even light, and so everyone will die." Even those who live today are but a pale shadow of the ancients. According to old Custodio, many are charlatans, who fail to diet properly, or who have sex with mestizos. Only when the blood is pure can psychotropics have their 
full effect; otherwise, before you know it the lightning will rain down and scorch the earth, until even the rivers will burn, and we will all be lost. Hence the need for people to live well, that is, morally: to share their food, to invite their neighbors to eat with them, to get along with others.

Catastrophic climate change is ultimately less a technical than a social and moral problem. As Ballard (2000: 206) writes, one of the distinctive features of any eschatology is that it provides the universe not just with a sense of trajectory, but with particular prescriptions for moral engagement with it. The idea of the apocalypse unloads a moral burden and imposes it with urgency. ${ }^{3}$ Drinkers of ayahuasca, in particular, can still act as a stabilizing force, counteracting cosmic and moral entropy, much as they did when the world almost ended so long ago:

Before, at the time when the world-era was almost finished, when the world was trembling, those good thunder-people were here, and they repaired it, they saved it. It's because they repaired it that it's lasting up until today. But it's almost about to end, just like that. That's why, because it wants to end, the drinkers of ayahuasca continue maintaining it, maintaining it just there, and because of that, thanks to them, the world continues.

Urarina shamanism is largely a set of techniques for the promotion of health, fertility, and world renewal, in which the tide of cosmic decline is momentarily thwarted. Drinkers of ayahuasca are thus sometimes referred to as cana cojoanona nunera (literally "our world-era's support"), and are widely seen as moral beacons on a cosmic scale, courageous as well as wise and persistent, leading a highly disciplined lifestyle in the pursuit of the preservation of life. In the altered states of consciousness induced following the consumption of ayahuasca or brugmansia, they are uniquely capable of requesting Our Creator to bring about replenishment of animals in the forest, the health of ill people in their care, fine weather, and the postponement of the apocalypse. That they ask for all these things simultaneously indicates the extent to which they are interconnected in Urarina thought, perhaps inseparable. Well-being, natural abundance, time, and the weather are all forms of the common good, not only held in common but continuously and collectively produced. 


\section{CONCLUSION}

In the Urarina language, as in many of the world's languages, the same term can refer both to "weather" and to "time." In most European languages today where this is the case the terms are effectively homonyms - that is, the same word can mean either, but not both at once, even though these meanings were once presumably inseparable. This makes sense, given the experiential connection here between the passing of time as marked in the change from day to night and from season to season. In fact, it seems plausible to speculate that the gradual semantic split between "time" and "weather" may have much to do with the invention of modern time keeping: that with the rise of the clock in the early modern period time became something abstract and absolute, disconnected from the cycles of nature (Smith 2011). The Urarina remind us that, ultimately, weather is time, or rather time is a form of weather. In this sense, acknowledging some scope for human intervention in the weather-something altogether common throughout human history-is not entirely different from acknowledging the possibility of intervening in the passing of time itself. In the wake of recent attempts to move beyond the nature/culture dichotomy so long taken for granted in Western thought, I do wonder then about the possibilities for taking seriously a notion of anthropogenic time, or the ways in which time is manipulated or otherwise brought within the remit of human agency-what Ringel and Morosanu (2016: 17) have recently termed "time-tricking," or "the many different ways in which people individually and collectively attempt to modify, manage, bend, distort, speed up, slow down or structure the times they are living in." The kind of time-tricking we are dealing with here seems an ancient one indeed. Michel Serres (1995: 48) writes:

In the temples of Egypt, Greece, or Palestine, our ancestors, I believe, used to sustain time, as if they were anxious about possible gaps. Here we are today, worried about disasters in the aerial protective fabric that guarantees not time passing, but the weather. They used to connect, assemble, gather, lift up, never ceasing all day long, like monks. And what if it turned out that human history and tradition exist simply because men devoted to the longest term conceivable have never stopped sewing time back together?

We return here to the challenge presented by climate change, as causing what Chakrabarty (2009) describes as "the collapse of the age-old humanist 
distinction between natural history and human history." An intervention into the climate is an intervention into time itself, and vice versa.

Yet, for all the possibilities afforded by human temporal agency, everything deteriorates sooner or later in the fluid Urarina cosmos. This is a harsh environment, remember: the general pattern is simply for things to decay and degrade sooner or later. In this view the weatherworld, our epoch, as a kind of massively distributed hyperobject, in the sense proposed by Timothy Morton (2013), can also be said to be subject to degradation. Cosmological entropy, in other words, has a likely foundation in the routine phenomenological experience of disintegration and decay, in an environment in which nothing stays still.

Let me finish by returning to the concept of cana cojoanona ("our world" or "our epoch"). I have described how it embodies a sense of both time and weather, but have said little about the first-person plural possessive marker. What precisely makes this world or epoch "ours," that is, proper to humankind? I can only speculate, but let us consider again the notion that everything decays at its own rate including the world itself. We might say that every object has its own eschatology, its own temporal horizon. This is clear enough in the case of cana cojoanonathe world literally is time, and time is always directional, always a measure of entropy. But the world decays just like everything else, albeit at a different rate. We might say that every entity has its own time, both in a physical and in a deep ontological sense, and therefore its own eschatology. Put differently, time is perhaps deeply relative, and not a neutral container through which persons or objects drift, so much as an emission of objects themselves (Morton 2013). In the absence of modern time-keeping devices that might give rise to a sense of abstract time, there is nothing outside of the life span of each concrete entity. The immense timescale of the world itself is not that of human affairs; climate is the life cycle of the cosmos. Outside the world, differentiating between now and then is meaningless; an event cannot straightforwardly be specified as happening at a certain place or at a certain time. This is, perhaps, why people can say that the world has in a sense already ended. A single cataclysmic event so far as the world is concerned is massively distributed through time from a human perspective. The shadow of the apocalypse looms out of the past as well as the future, in a kind of temporal foreshortening, with its wake of causality flowing into the present from both directions, threatening but never entirely overcoming the possibility of courageous action by humankind to save it. 


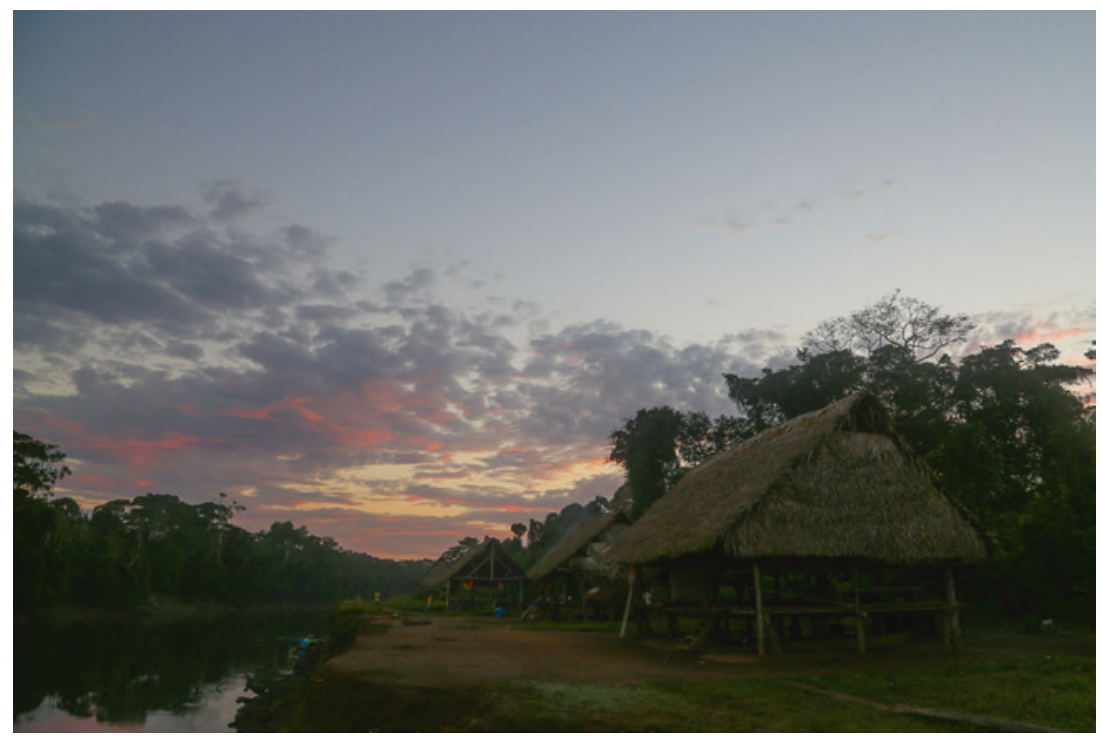

Acknowledgement This research has received funding from the European Research Council under the European Union's Horizon 2020 research and innovation programme (grant agreement No 715725).

\section{Notes}

1. The associative prefix "co-" links janonaa to the first person plural pronoun cana, with resultant vowel spreading across the " $j$."

2. Ingold (2012: 76) points out that several semantically distinct words have a common root in the Latin tempus, including the verb temperare ("to mix") (from which both temperature and temperate derive), as well as temper and temperament, words used to describe human moods and dispositions. "The blending of these different roots is indeed no accident," he writes, "for the weather is a phenomenon of both time and mixture, and of both our affective lives and the aerial medium in which these lives are led."

3. Amanat (2002: 4) argues that an apocalyptic calendric may be "far more essential for the continuity of the sacred and its perpetual renewal than our modern utilitarian notion of linear time and the concept of progress. Time cycles thus may be seen as regulatory means of placing utopian and eschatological aspirations, and whatever is associated with the Beginning and the End, within a humanly conceivable time-frame." 


\section{REFERENCES}

Amanat, Abbas. 2002. "Introduction: Apocalyptic Anxieties and Millenial Hopes in the Salvation Religions of the Middle East." In Imagining the End: Visions of Apocalypse from the Ancient Middle East to Modern America, edited by Abbas Amanat and Magnus T. Bernhardsson, 1-22. London and New York: I.B. Tauris.

Ballard, Chris. 2000. "The Fire Next Time: The Conversion of the Huli Apocalypse." Ethnohistory 47 (1): 205-225.

Bessire, Lucas. 2011. "Apocalyptic Futures: The Violent Transformation of Moral Human Life Among Ayoreo-Speaking People of the Paraguayan Gran Chaco." American Ethnologist 38 (4): 743-757.

Chakrabarty, Dipesh. 2009. "The Climate of History: Four Theses." Critical Inquiry 35: 197-222.

Danowski, Déborah, and Eduardo Viveiros de Castro. 2017. The Ends of the World. Cambridge: Polity Press.

Fenn, Richard. 2003. "Apocalypse and the End of Time." Daedalus 132 (2): 108-112.

Haley, Nicole. 1996. "Revisioning the Past, Remembering the Future: Duna Accounts of the World's End." Oceania 66: 278-285.

Harkin, Michael E. 2012. "Anthropology at the End of the World." Reviews in Anthropology 41: 96-108.

Ingold, Tim. 2007. "Earth, Sky, Wind, and Weather." Journal of the Royal Anthropological Institute 13: S19-S38.

Ingold, Tim. 2012. "The Atmosphere." Chiasmi International 14: 75-87.

Lee, Jane. 2014. "Lunar Eclipse Myths from Around the World." National Geographic. Published 14 April 2004. Available at http://news.nationalgeographic. com/news/2014/04/140413-total-lunar-eclipse-myths-space-culture-science/.

Lewis, Simon, and Mark Maslin. 2015. "Defining the Anthropocene." Nature 519 (12 March): 171-180.

Marx, Karl, and Frederick Engels. 2010 [1848]. Manifesto of the Communist Party. Marxists Internet Archive.

Morton, Timothy. 2013. Hyperobjects: Philosophy and Ecology After the End of the World. Minneapolis: University of Minnesota Press.

Neves Marques, Pedro. 2015. "Look Above, The Sky Is Falling: Humanity Before and After the End of the World." e-flux (online journal). Available at http://supercommunity.e-flux.com/texts/look-above-the-sky-is-falling-humanity-before-and-after-the-end-of-the-world/. Accessed 15 September 2017.

Ringel, Felix, and Roxana Morosanu. 2016. "Time-Tricking: A General Introduction." The Cambridge Journal of Anthropology 34 (1): 17-21.

Serres, Michel. 1995. The Natural Contract. Ann Arbor, MI: University of Michigan Press.

Smith, Justin. 2011. "Being and Weather." The New York Times, 29 August. 
Open Access This chapter is licensed under the terms of the Creative Commons Attribution 4.0 International License (http://creativecommons.org/licenses/ by $/ 4.0 /)$, which permits use, sharing, adaptation, distribution and reproduction in any medium or format, as long as you give appropriate credit to the original author(s) and the source, provide a link to the Creative Commons license and indicate if changes were made.

The images or other third party material in this chapter are included in the chapter's Creative Commons license, unless indicated otherwise in a credit line to the material. If material is not included in the chapter's Creative Commons license and your intended use is not permitted by statutory regulation or exceeds the permitted use, you will need to obtain permission directly from the copyright holder.

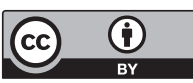

